\title{
(C) OPEN ACCESS \\ Deprescribing medicines in the acute setting to reduce the risk of falls
}

\author{
Vanessa Marvin, ${ }^{1}$ Emily Ward, ${ }^{1}$ Alan J Poots, ${ }^{2}$ Katie Heard, ${ }^{1}$ Arvind Rajagopalan, ${ }^{3}$ \\ Barry Jubraj ${ }^{2,4}$
}

- Additional material is published online only. To view please visit the journal online (http://dx.doi.org/10.1136/ ejhpharm-2016-001003).

${ }^{1}$ Department of Pharmacy, Chelsea and Westminster Hospital NHS Foundation Trust, London, UK

${ }^{2}$ NIHR CLAHRC NWL, Imperial College London, London, UK ${ }^{3}$ School of Medicine, Imperial College London, London, UK ${ }^{4}$ Institute of Pharmaceutical Sciences, King's College London, London, UK

\section{Correspondence to} Dr Vanessa Marvin, Department of Pharmacy, Chelsea and Westminster Hospital NHS Foundation Trust, 369 Fulham Road, London SW10 9NH, UK; vanessa. marvin@chelwest.nhs.uk

Received 27 May 2016 Revised 22 July 2016 Accepted 28 July 2016 Published Online First 19 August 2016

EAHP Statement 4: Clinical Pharmacy Services

\begin{abstract}
Background Falls are a common cause of morbidity and hospitalisation in older people. Inappropriate prescribing and polypharmacy contribute to falls risk in elderly patients. This study's aim was to quantify the problem and find out if medication review in the hospital setting led to deprescribing of medicines associated with falls risk.
\end{abstract}

Methods Admissions records for elderly patients were examined to identify those whose presenting complaint included a fall. Inpatient medication charts,

pharmaceutical care notes, medical notes and discharge summaries were examined to identify any falls-risk medicines from admission histories and to determine if any medication review took place, and whether or not changes were made as a result. In particular deprescribing and dose reduction details were analysed. Results 100 patients over 70 years old were admitted following a fall during the 2 months study period. The mean number of medicines on admission was 6.8 per patient with polypharmacy found in $62 / 100(62 \%)$. One or more falls-risk medicine was found in 65/100 (65\%) patients. Medicines review was carried out in $86 / 100$ $(86 \%)$ of patients, and 59/697 (8.5\%) medicines were deprescribed. Pharmacist involvement in medication review led to a significant reduction in the number of falls-risk medicines per patient ( $p=0.002$ ).

Conclusions Inappropriate prescribing and polypharmacy are found frequently in elderly patients at admission following a fall. Comprehensive medicines reviews should be carried out in all such patients with the objective of deprescribing or reducing doses to minimise risk of harm. Involvement of a pharmacist improves the rate of reduction of falls-risk medicines.

\section{INTRODUCTION}

Improving patient outcomes through medicines optimisation is a national priority and a key part of the work being undertaken by the National Institute for Health Research Collaboration for Leadership in Applied Health Research and Care North West London (CLAHRC NWL) particularly in older people who have frailty.

Falls in elderly patients are a common cause of morbidity and an increasing reason for presentation to hospital. ${ }^{1}$ With advancing age and frailty there is increased chance of multimorbidity ${ }^{2}$ and prescription of potentially inappropriate medicines, some of which may contribute to risk of falls. ${ }^{3}$ Although medications may be indicated at the time of diagnosis, they should be regularly reviewed as later they may have more potential for harm and no longer provide overall benefit. ${ }^{3}$
Polypharmacy is independently associated with negative outcomes in frailty particularly where there is decline in nutritional status, functional ability and cognitive capacity. ${ }^{4}$ Specifically, it has been shown that it increases the risk of falls in elderly populations and problematic polypharmacy is therefore recognised as a potentially modifiable contributing factor in falls and frailty. ${ }^{5}$

Freeland et al found that among patients aged 65 years and older who have experienced a fall in the past year, the addition of each medication above four increases their fall risk by $14 \%{ }^{6}$ Similarly, Damian et al found that each added medicine increased physician-reported falls in the preceding 30 days by $7 \% .^{7}$ These findings corroborate earlier prospective cohort studies which have shown that increasing medication use is associated with increased falls-risk scores in elderly patients. $^{89}$

Further to this, the simultaneous discontinuation of many drugs was found to be 'safe' and appears to improve quality of life in elderly community dwellers. $^{10}$

Other studies demonstrate that multiple medication lists in elderly patients are more likely to include falls-risk medicines. A systematic review found that benzodiazepines, antidepressants, antihypertensives and antipsychotics are among the most common medicines to be prescribed to older people with polypharmacy. ${ }^{11}$

A prospective cohort study of older adults coming into hospital following a fall, found that compared with robust elderly, those with frailty were prescribed a significantly higher number of falls-risk medicines. The number prescribed on discharge was additionally significantly associated with recurrent falls. ${ }^{12}$

The National Institute for Health and Care Excellence (NICE) 2015 Quality Standard 86 includes the statement: 'older people who present for medical attention because of a fall should have a multifactorial falls-risk assessment including cardiovascular examination and a medication review'. ${ }^{1}$

Medication review has been defined as 'any systematic assessment of the pharmacotherapy of an individual patient that aims to evaluate and optimise patient medication by a change in prescription either by a recommendation or by a direct change'. ${ }^{13}$ As part of the wider CLAHRC project on medicines optimisation in frailty, we defined levels of medication review in hospital ${ }^{14}$ (box 1).

Interim reviews can be doctor or pharmacist led (especially as part of medicines reconciliation on admission); the timing and breadth of the changes are adjusted according to patient need with their 
Box 1 CLAHRC NWL definitions of 'medication review' levels ${ }^{14}$

Comprehensive medication review

- This is a full review using a structured critical examination of all current medication with the objective of reaching an agreement with the patient about continuing treatment. The reviewer systematically considers the benefits and risks of different medications, stops inappropriate medicines and starts others.

Interim medication review

- In the acute hospital setting, reviews leading to short-term medication changes frequently take place; these we have defined as interim. Medicines are reviewed when a patient presents acutely unwell at hospital or when their condition deteriorates or improves. Individual medicines may be changed or held because they are considered 'non-essential' or currently 'unnecessary' or as part of the preoperative assessment process. In addition in these settings, medicines are stopped if they are identified as contributing to morbidity.

immediate safety and well-being central to the decision but not necessarily with their full knowledge or participation (in contrast to comprehensive review). Some reviews may lie between the two categories so for 'comprehensive' we require the patient to be involved (or their carer if capacity is impaired) and a senior clinician (doctor or pharmacist) to lead.

It is imperative, however, to acknowledge that a condition for medication review is reliable medicines reconciliation at admission and discharge from hospital. ${ }^{15}$ Any review process typically begins with confirmation of a patient's current medication; if inaccurate, decisions may be made based on the wrong information. ${ }^{16}$ Therefore, prescribing and deprescribing is safe only in the context of a full understanding of the patient's drug history.

In order to support clinicians in reducing potentially inappropriate prescriptions (PIP) and optimise therapy, a PIP list for older patients was developed locally ${ }^{17}$ directly from the STOPP criteria of O'Mahony et $\mathrm{al}^{3}$ (see online supplementary appendix A). From this we further developed a deprescribing support tool 'STOPIT', used previously in an earlier version. ${ }^{18} 19$ The tool includes a section on medicines known to contribute to falls, commonly through orthostatic hypotension and sedation. ${ }^{3}$ These falls-risk medicines are listed in box 2 .

Opioids are included as they are linked with falls through sedation and confusion, particularly in the vulnerable elderly. ${ }^{20} 21$ All medicines with anticholinergic properties or side effects are implicated in falls and are therefore included in our list of 'falls-risk medicines'22 23 (see box 2).

Other medicines may indirectly induce falls through mechanisms including vasovagal syndrome, carotid sinus hypersensitivity, bradycardia, tachycardia, periods of asystole $^{24}$ and hypoglycaemia. These medicines are not on our definitive list for falls risk but their effects, risks and benefits in vulnerable patients are considered in a comprehensive review.

\section{Aims and objectives}

Our aim was to identify patients affected by falls, and find whether medication review in the acute setting led to deprescribing of falls-risk medicines.

\section{Box 2 Falls-risk medicines (adapted from 0'Mahony et $a^{3}$ )}

- Antimuscarinics/anticholinergics and those with anticholinergic side effects, for example, amitriptyline, chlorphenamine, loperamide.

- ACE inhibitors and angiotensin receptor blockers.

- $\alpha$ blockers.

- Antipsychotics.

- Benzodiazepines and 'Z drugs'.

- Calcium channel blockers.

- Long acting nitrates.

- Vasodilator antihypertensives used in heart failure.

- Opioids.

Specific objectives were to:

- Identify all admissions aged over 70 years following a fall, on polypharmacy or problematic medicines.

- Examine hospital clinician involvement in medication review.

- Quantify nature and extent of deprescribing.

\section{Ethical approval}

Ethics approval was not required for this work as it is part of a service evaluation and improvement project. An ethics waiver was granted by Chelsea and Westminster Hospital NHS Foundation Trust Research and Development lead and National Research Ethics Service (NRES).

\section{Setting}

The study was conducted at Chelsea and Westminster Hospital, London (CWH) supported by CLAHRC NWL. Across all specialties, CWH admits an average of 740 adults a month, approximately 500 of whom are 70 years and older.

\section{METHODS}

Admissions coding data and emergency department discharge summaries (DSUMs) for the period 02 February 2015 to 31 March 2015 were examined to identify patients who were aged 70 years or older who were known to have had a fall and were in hospital as a result overnight. Recruited patients were followed-up prospectively, and data obtained from medical records and electronic prescribing records. All patients were seen by their usual pharmacist during their regular visits to the ward. Screening of prescriptions and documentation of pharmaceutical care contributions were undertaken as per ward pharmacy inpatient standard procedures. Weekly consultant ward rounds were attended by pharmacists as part of routine practice. No specific research interventions were made, however, all pharmacists were aware of the project through departmental teaching sessions aimed at improving communications regarding medication changes.

Final DSUMs were checked retrospectively for documentation of medication reviews and any changes made to regular medicines.

All data was collated by research student (AR) supervised by a specialist pharmacist (EW).

A database was created for this cohort including details of the following:

- Medicines reconciliation on admission verified as 'reliable' by a pharmacist according to local policy.

- Medicines review documented as having taken place and by whom.

- Pharmacist role in any medication review or change. 
- Changed doses and formulations.

- Newly prescribed medicine(s) and indication.

- Deprescribed and held medicine(s) and whether potentially contributed to the risk of falls (box 2).

Medicines purchased over the counter for acute use 'as required' were not included as regular medication. Neither were acute courses of, for example, antibiotics and simple (nonopiate) analgesia.

We define polypharmacy as the prescription of six or more regular medicines as used by other researchers. ${ }^{25}$ 'Appropriate' polypharmacy requires that all medicines have a clear indication and are not PIPs. ${ }^{17}$

Descriptive statistics were performed and falls-risk medicines prescribed before and after review were compared using the Kruskal-Wallis test for significant difference in rank.

\section{RESULTS} or over during the study period was 1020, of whom $126(12 \%)$ were identified having presented following a fall. Of these patients, 26/126 (21\%) were 'lost to follow-up by pharmacists' as they were discharged from the Emergency Observation Unit without a prescription or other identifiable documentation about medication.

The remaining 100 were included in the analysis: the mean age was 85 years, the oldest was 101 years old; 61/100 (61\%) were female. One patient was recorded as having an additional falls admission within the project period.

\section{Medications reconciliation and review}

Medicines reconciliation was reliable on admission for $80 / 100$ $(80 \%) ; 3 / 100(3 \%)$ patients were not on any regular medication from admission through to discharge and 4/100(4\%) patients died during the inpatient episode.

Medication review was documented as having taken place with or without changes to regular medicines in $86 / 100(86 \%)$. Fifty-eight (58\% of patients) of these medication reviews were comprehensive; in five $(5 \%)$ cases there is documentation regarding pharmacist reconciliation and review but not by the doctor and in two (2\%), the doctor documented 'review' but the pharmacist had not completed medicines reconciliation on admission. In the remaining 21/86 documented 'reviews' the involvement of the patient or their carer is not clear. These were noted as interim reviews.

\section{Prevalence of polypharmacy}

In total, 679 medicines were taken by 100 patients before any medication review took place, a mean of 6.8 per patient (range $0-18$, including unconfirmed medications).

Polypharmacy was present in 62/100 (62\%) patients, and problematic polypharmacy (the patient was taking at least one medication identified as potentially inappropriate) was found in $57 / 62(92 \%)$ of those with polypharmacy; or $57 / 100(57 \%)$ of all patients. Fifty-five out of $62(89 \%)$ polypharmacy admissions had a documented medication review.

Polypharmacy was found in more patients at discharge than at admission in the cohort of 100: while 5/62 (8\%) polypharmacy patients were no longer on six or more medicines after review, 9/38 (24\%) non-polypharmacy patients returned home with six or more medicines: thus 66/100 (66\%) patients were discharged from hospital with polypharmacy. Bisphosphonates and vitamin D accounted for $49 / 54(91 \%)$ of the newly prescribed medicines.

\section{Identification of patients with a history of falls}

The total number of admissions to CWH for patients aged 70

\section{Falls-risk medications}

One hundred and twelve out of 679 (16.5\%) admission medicines were falls-risk medicines taken by 65 patients (table 1 ): $30 / 112(26.7 \%)$ of falls-risk medicines were reduced or stopped. A Kruskal-Wallis test is used to find a significant reduction $(p=0.004)$ in number of falls-risk medicines on these patients' prescriptions postreview (91) compared with at admission (112).

Of the $65 / 100(65 \%)$ patients found to be on a falls-risk medicine, $29 / 65$ (45\%) had no reduction in medication including $12 / 65$ (18\%) who had no documented medicines reconciliation. Six out of $65(9 \%)$ did have a review and no changes were made to falls-risk medicines; other prescription items were started or doses increased in these cases. Twenty-three out of 65 (35\%) patients had a comprehensive review which led to reduction of falls-risk medicines and 5/65 (8\%) were no longer on any by discharge.

\section{Medication changes}

Overall, 38/100 (38\%) patients had their regular prescriptions reduced in some way while in hospital. A total of $75 / 697$ (10.8\%) medicines were affected: 59/697 (8.5\%) of all medicines were deprescribed, $12 / 697(1.7 \%)$ were reduced to a lower dose and 4/697 (0.6\%) medicines were held pending further review (table 2).

Of these changed medicines, 29/75 (39\%) were falls-risk medicines in 21 patients (table 2). However, while there was a decrease in falls-risk medicines following review, after changes were made to regular medicines in hospital there was a net increase to 733 in the total number of medicines prescribed for the cohort. A list of all medicines deprescribed is in online supplementary appendix B.

\section{Pharmacist involvement}

Pharmacists were involved in 45/86 (52\%) cases where it was documented that a medication review had taken place (with or without changes made). The number of falls-risk medicines decreased by a mean of 0.53 per patient before and after review in these 45 (not including the dose reductions). A Kruskal-Wallis test finds a significant reduction between the numbers before and after review $(p=0.002)$. Of note, in all cases where medication review led to a reduction in falls-risk medicines for a patient a pharmacist was involved and the changes were documented.

Table 1 Medicines taken by elderly falls patients

\begin{tabular}{|c|c|c|c|}
\hline $\mathrm{n}=100$ patients & $\begin{array}{l}\text { On } \\
\text { admission }\end{array}$ & $\begin{array}{l}\text { At } \\
\text { discharge* }\end{array}$ & Difference \\
\hline No. of regular medicines & 679 & 733 & +54 \\
\hline No. of FRM & 112 & 91 & $\begin{array}{l}-21 \\
(p=0.004)\end{array}$ \\
\hline Patients on $\geq 1$ FRM & 65 & 60 & -5 \\
\hline$\%$ of all medicines that are FRM & $16.4 \%$ & $12.4 \%$ & $-4 \%$ \\
\hline Mean FRM/patient reviewed $n=82$ & 1.19 & 0.939 & -0.26 \\
\hline $\begin{array}{l}\text { Mean FRM/patient reviewed with } \\
\text { pharmacist involved } n=45\end{array}$ & 1.44 & 0.91 & $\begin{array}{l}-0.53 \\
(p=0.002)\end{array}$ \\
\hline $\begin{array}{l}\text { FRM per patient not reviewed } \\
n=18 \dagger\end{array}$ & 0.77 & 0.77 & 0 \\
\hline \multicolumn{4}{|c|}{$\begin{array}{l}\text { *Including four patients who died in hospital. } \\
\text { tIncludes three patients on no medicines from admission through to discharge } \\
\text { therefore not reviewed in this context. } \\
\text { FRM, falls-risk medicine. }\end{array}$} \\
\hline
\end{tabular}


Table 2 Falls-risk medicines deprescribed, held or reduced

\begin{tabular}{|c|c|c|}
\hline Patient & Medicine & $\begin{array}{l}\text { Deprescribed (D) } \\
\text { Held (H) } \\
\text { Reduced dose (R) }\end{array}$ \\
\hline 1 & Tramadol & D \\
\hline 2 & Fentanyl & D \\
\hline 3 & $\begin{array}{l}\text { Lercanidipine } \\
\text { Losartan }\end{array}$ & $\begin{array}{l}D \\
D\end{array}$ \\
\hline 4 & Ramipril & $\mathrm{D}$ \\
\hline 5 & $\begin{array}{l}\text { Buprenorphine } \\
\text { Doxazosin }\end{array}$ & $\begin{array}{l}\mathrm{D} \\
\mathrm{R}\end{array}$ \\
\hline 6 & Buprenorphine & $\mathrm{D}$ \\
\hline 7 & $\begin{array}{l}\text { Lercanidipine } \\
\text { Lisinopril } \\
\text { Moxonidine }\end{array}$ & $\begin{array}{l}D \\
D \\
D\end{array}$ \\
\hline 8 & Tramadol & $\mathrm{D}$ \\
\hline 9 & Isosorbide mononitrate & $\mathrm{D}$ \\
\hline 10 & Ramipril & $\mathrm{D}$ \\
\hline 11 & Tolterodine & $\mathrm{D}$ \\
\hline 12 & $\begin{array}{l}\text { Losartan } \\
\text { Tramadol }\end{array}$ & $\begin{array}{l}D \\
D\end{array}$ \\
\hline 13 & Amlodipine & $\mathrm{D}$ \\
\hline 14 & $\begin{array}{l}\text { Amitriptyline } \\
\text { Isosorbide mononitrate } \\
\text { Ranolazine }\end{array}$ & $\begin{array}{l}D \\
D \\
D\end{array}$ \\
\hline 15 & Oxybutynin & $D$ \\
\hline 16 & Diazepam & $\mathrm{D}$ \\
\hline 17 & Ramipril & $\mathrm{R}$ \\
\hline 18 & Lisinopril & $\mathrm{D}$ \\
\hline 19 & Irbesartan & $\mathrm{H}$ \\
\hline 20 & $\begin{array}{l}\text { Cetirizine } \\
\text { Amlodipine }\end{array}$ & $\begin{array}{l}\mathrm{D} \\
\mathrm{H}\end{array}$ \\
\hline 21 & Zopiclone & D \\
\hline
\end{tabular}

\section{DISCUSSION}

A fall, whether or not an injury is sustained, is a common reason for patients aged 70 or older to present to hospital. We identified 126 patients in a period of 2 months who were admitted (for at least one night) from a total of 1020 admissions recorded in this age group during this time (12\%). We followed-up a cohort of 100,97 of whom were on regular medication from admission. Polypharmacy, defined as six or more medicines was prevalent $(62 \%)$ with an average of 6.8 per patient. In just five polypharmacy patients, all medicines were considered appropriate in the context of their age and history of falls.

We identified problematic polypharmacy in $57 \%$ of our cohort (inpatients over 70 years old who had fallen prior to admission). PIPs have previously been estimated to occur in about a third of older patients. ${ }^{26}{ }^{27}$ Our identified PIPs included all anticholinergics, known to contribute to falls but we would argue many medicines are unrecognised as being in this category. We note one small study of anticholinergic burden and falls identified regular anticholinergic prescriptions in $22 \%$ of patients, ${ }^{28}$ and using their criteria only $10 \%$ of patients had no identified risk of falls from their medicines. We used a shorter, evidence-based list of falls-risk medicines, though inclusive of all anticholinergics and found $65 \%$ of our patients on one or more. The association of anticholinergics with falls has been reaffirmed in a community study in men over 65 years. ${ }^{29}$

Despite the increase in the number of polypharmacy patients (nine more at discharge than on admission), we have shown that review improved prescribing and optimised medicines overall.
The increase was due largely to the prescribing of calcium and vitamin D supplementation in our cohort; these additional medicines are considered appropriate according to the STOPP/ START criteria ${ }^{3}$ although an alternative view is emerging which may lead to further consideration of local guidelines. ${ }^{30}$

The NICE pathway on falls in older people recommends that those on 'psychotropic' medicines should have their medication reviewed, with a specialist input if appropriate, and discontinued if possible to reduce their risk of falling. ${ }^{1}$ We did not include all medicines affecting mood; only antipsychotics, benzodiazepines and 'z-drugs' which are considered directly linked with falls. We may therefore need to update our list (box 2); if we had included all psychotropics the number of falls-risk medicines on admission in our study would be increased by 16 to a total of 128 .

A study by Browne et al and colleagues in 2014 looked at 50 inpatients at risk of falls and found that only $20 \%$ of falls-risk medicines were suitable for change after reviews, which were found to be time and resource intensive. ${ }^{31}$ However, the authors suggest targeting resources to those on polypharmacy (four or more in their study) including as required (prn) rather than restricting to 'regular' medications results in greater deprescribing rates. ${ }^{31}$ Another study demonstrated that the risk of subsequent falls is reduced in patients for whom falls-risk medicines are reduced, ${ }^{32}$ suggesting that it is an effective use of resource if the medical cost of a fall is taken into account.

We have put in place specific tools to prompt safe, patientcentred deprescribing when falls-risk medicines are identified and although we did not measure their uptake and use in this project, we are further promoting STOPIT and teaching about PIPs to junior staff. We believe pharmacists can and should be more proactive in stopping medicines ${ }^{33}$ and such tools encourage and promote good prescribing practice. This is supported by our finding that suggests pharmacist involvement in medication reviews significantly reduces the number of falls risk medicines. However, the mean reduction in number was less than one drug $(0.53)$ per patient. The benefit in terms of reducing falls is unclear but there are other benefits of stopping medicines, such as decreased pill burden and costs. We plan to measure these with follow-up of a larger cohort, also checking for readmissions and further falls over a longer period.

Our recommendation is to involve pharmacists in identifying patients at risk, beginning the process of comprehensive medication review from the point of verifying the drug history (in line with Royal Pharmaceutical Society standards ${ }^{34}$ ) and prompting the prescriber at all stages of the patient journey through the hospital and at transfer. For this we may need to improve knowledge and understanding of anticholinergic medicines and switch patients' prescriptions to lower anticholinergic burden when they are at risk of falls (or confusion). ${ }^{35}$ In addition, we would explore ways in which the electronic prescribing record system could alert to the need for a medicines review following medicines reconciliation documentation as described by Graabaek et al. ${ }^{36}$

\section{Limitations}

The period of study was February and March 2015. These months may not be typical; seasonal variation in falls rates is likely. However, prescribing of falls-risk medicines is not expected to vary with time of year.

It is unclear if the number of reviews documented is a true reflection of the number actually carried out on elderly patients admitted following a fall. Reviews without changes being made are under-represented. 
Only regular medicines meant for long-term continuation were included in our analysis. We, therefore, excluded acute use of several contributors to falls risk, for example, sedating antihistamines, if they were as required medicines. Further to this our definitive falls-risk medicine list was limited to those with evidence linking them to actual falls. Other antihypertensive medicines such as $\beta$-blockers are implicated, for example, if the patient experiences a postural drop in blood pressure; there is a case for extending our list to include these in line with other published data. $^{37}$

\section{CONCLUSION}

Inappropriate prescribing and polypharmacy are found frequently in elderly patients at admission following a fall. Comprehensive medicines reviews should be carried out in all such patients with the objective of deprescribing or reducing doses to minimise risk of harm. This is significantly more likely to be achieved with a pharmacist input. We suggest involving pharmacists in reviews from the start of medicines reconciliation at admission (earlier where possible), improving recognition of falls-risk medicines by all clinicians and supporting prescribers in deprescribing.

\section{What this paper adds?}

\section{What is already known on this subject?}

- Anticholinergic, sedative and hypotensive medicines increase risk of falls in elderly patients.

- Falls are a common reason for admission to hospital in older people and an increasing burden on healthcare services.

- Polypharmacy is associated with negative outcomes in frailty.

\section{What this study adds?}

- Medicines known to contribute to falls risk are taken by $65 \%$ of elderly patients admitted to hospital locally following a fall.

- Problematic polypharmacy is a common finding in those over 70 years old.

- Following review of medication particularly where a pharmacist makes a contribution, deprescribing leads to a significant reduction in prescriptions for falls-risk medicines.

\section{Twitter Follow Emily Ward at @emward_pharm}

Acknowledgements Inaki Bovill and Peter Kroker consultant physicians for the elderly at CWH who worked closely with us on this project; Laurel Issen and Susan Barber for their Quality Improvement support from CLAHRC. This article presents independent research commissioned by the NIHR under the CLAHRC programme for NW London. The views expressed in this publication are those of the authors and not necessarily those of the NHS, NIHR or the Department of Health.

Contributors VM, EW, AJP, KH, AR, BJ all contributed to data collation, analysis and write up. All were pharmacists at CWH at the time of the project except AJP: Principal Information Analyst, NIHR CLAHRC NWL and AR: Medical Student at Imperial College London.

Competing interests None declared.

Provenance and peer review Not commissioned; externally peer reviewed.

Data sharing statement All data as before available through the corresponding author including STOPIT tool, PIP list and further information regarding statistical analysis.
Open Access This is an Open Access article distributed in accordance with the Creative Commons Attribution Non Commercial (CC BY-NC 4.0) license, which permits others to distribute, remix, adapt, build upon this work non-commercially, and license their derivative works on different terms, provided the original work is properly cited and the use is non-commercial. See: http://creativecommons.org/ licenses/by-nc/4.0/

\section{REFERENCES}

1 National Institute for Health and Care Excellence (NICE). Falls in older people. http://pathways.nice.org.uk/pathways/falls-in-older-people (accessed 26 Jan 2016).

2 Oliver D, Foot C, Humphries R. Making our health and care systems fit for an ageing population. London: The King's Fund, 2014. http://www.kingsfund.org.uk/ publications/making-health-care-systems-fit-ageing-population (accessed 15 Jan 2016).

3 O'Mahony D, O'Sullivan D, Byrne S, et al. STOPP/START criteria for potentially inappropriate prescribing in older people: version 2. Age Ageing 2015;44:213-18.

4 Jyrkkä J, Enlund $\mathrm{H}$, Lavikainen $\mathrm{P}$, et al. Association of polypharmacy with nutritional status, functional ability and cognitive capacity over a three-year period in an elderly population. Pharmacoepidemiol Drug Saf 2011;20:514-22.

5 Duerden M, Avery T, Payne R. Polypharmacy and medicines optimisation: making it safe and sound. London: The King's Fund, 2013. http://www.kingsfund.org.uk publications/polypharmacy-and-medicines-optimisation (accessed 15 Jan 2016).

6 Freeland KN, Thompson AN, Zhao Y, et al. Medication use and associated risk of falling in a geriatric outpatient population. Ann Pharmacother 2012:46:1188-92.

7 Damian J, Pastor-Barriuso R, Valderrama-Gama E, et al. Factors associated with falls among older adults living in institutions. BMC Geriatr 2013;13:6-2318-13-6

8 Tromp A, Pluijm S, Smit J, et al. Fall-risk screening test: a prospective study on predictors for falls in community-dwelling elderly. J Clin Epidemiol 2001;54:837-44

9 Kojima T, Akishita M, Nakamura T, et al. Association of polypharmacy with fall risk among geriatric outpatients. Geriatr Gerontol Int 2011;11:438-44.

10 Garfinkel DG, Mangin D. Feasibility study of a systematic approach for discontinuation of multiple medicines in older adults. Arch Intern Med 2010;170:1648-54.

11 Hartikainen S, Lönnroos E. Use of sedatives and hypnotics, antidepressants and benzodiazepines in older people significantly increases their risk of falls. Evid Based Med 2010;15:59.

12 Bennett A, Gnjidic D, Gillett $M$, et al. Prevalence and impact of fall-risk-increasing drugs, polypharmacy, and drug-drug interactions in robust versus frail hospitalised falls patients: a prospective cohort study. Drugs Aging 2014;31:225-32.

13 Christensen M, Lundh A. Medication review in hospitalised patients to reduce morbidity and mortality. Cochrane Databse Syst Rev 2013(2):Art.No.:CD008986.

14 Szymanski T, Marvin V, Ward E, et al. Deprescribing following medication review in acute care: the ReMAC project. Abstract and presentation at the Pharmaceutical Care Network Europe, Hillerød, Denmark 2016. Conference abstract also published in Int J Clin Pharm (p17) DOI 10.1007/s11096-016-0283-8.

15 Marvin VA, Kuo S, Poots AJ, et al. Applying Quality Improvement methods to address gaps in medicines reconciliation at transfers of care from an acute UK hospital. BMJ Open 2016:6:e010230.

16 Royal pharmaceutical Society. Keeping people safe when they transfer between care providers - getting the medicine right: Good practice guidance for healthcare professionals July 2011. http://www.rpharms.com/medicines-safety/ getting-the-medicines-right.asp

17 National Institute for Health Research (NIHR) Collaboration for Leadership in Applied Health Research and Care (CLAHRC) http://clahrc-northwestlondon.nihr.ac uk/resources/pip

18 Abdul-Saheb M, Jubraj B, Bovill I, et al. Intermediate Care: An optimal setting for review of inappropriate medication in elderly patients? CME J Geriatr Med 2014;44:13-17

19 Jubraj B, Marvin V, Poots AJ, et al. A Pilot survey of junior doctors attitudes and awareness around medication review: time to change our educational approach? Eur J Hosp Pharm 2015;22:243-8.

20 NHS Scotland. Polypharmacy Guidance. 2015. http://www.sign.ac.uk/pdf/ polypharmacy_guidance.pdf

21 Söderberg KC, Laflamme L, Möller J. Newly initiated opioid treatment and the risk of fall-related injuries. CNS Drugs 2013;27:155-61.

22 Landi F, Dell'Aquila G, Collamati A, et al. Anticholinergic drug use and negative outcomes among the frail elderly population living in a nursing home. J Am Med Dir Assoc 2014:15:825-9.

23 BNF. 2016. https://www.medicinescomplete.com/mc/bnf/current/

24 Darowski A, Dwight J, Reynolds J. Medicines and Falls in Hospital: guidance sheet. March 2011. (Approved by the British Geriatrics Society for Frailsafe). (http://www. drugsandfalls.com)

25 Hilmer SN, Gnjidic D. The effects of polypharmacy in older adults. Clin Pharmacol Ther 2009;85:86-8. 
26 Cahir C, Fahey T, Teeling M, et al. Potentially inappropriate prescribing and cost outcomes for older people: a national population study. Br I Clin Pharmacol 2010;69:543-52.

27 Hamilton H, Gallagher P, Ryan C, et al. Potentially inappropriate medications defined by STOPP criteria and the risk of adverse drug events in older hospitalized patients. Arch Intern Med 2011;171:1013-19.

28 Chaudhry N. Using a 'MAP' to steer patients away from medicines-related falls. Clinical Pharmacist 2013:5:119-21.

29 Richardson K, Bennett K, Maidment I, et al. Use of medications with anticholinergic activity and self-reported injurious falls in older community dwelling adults. J Am Ger Soc 2015;63:1561-9.

30 Jarvinan T, Michaelsson $\mathrm{K}$, Jokihaara J, et al. Overdiagnosis of bone fragility in the quest to prevent hip fracture. BMJ 2015;350:18-20.

31 Browne C, Kingston C, Keane C. Falls prevention focused medication review by a pharmacist in an acute hospital: implications for future practice. Int I Clin Pharm 2014;36:969-75.
32 Van Der Velde N, Stricker BHC, Pols HA, et al. Risk of falls after withdrawal of fall-risk-increasing drugs: a prospective cohort study. Br I Clin Pharmacol 2007:63:232-7.

33 Duraisingham S, Jubraj B. Time to stop. Clinical Pharmacist 2014;6: 16221.

34 Royal Pharmaceutical Society. Professional Standards for Hospital Pharmacy Services: Optimising patient outcomes from Medicines v 2. London: RPS, 2014.

35 Lopez-Alvarez J, Zea Sevilla MA, Aguera Ortiz L, et al. Effect of anticholinergic drugs on cognitive impairment in the elderly. (Translation from original Spanish) Rev Psiquiatr Salud Ment (Barc) 2015;8:35-43.

36 Graabaek T, Bonnerup DK, Kjeldsen LJ, et al. Pharmacist-led medication review in an acute admissions unit: a systematic procedure description. Eur J Hosp Pharm 2015;22:202-6.

37 Davies EA, O'Mahony MS. Adverse drug reactions in special populations-the elderly. Br J Clin Pharmacol 2015;80:796-807. 